\title{
Human cerebral asymmetries evaluated by computed tomography
}

\author{
H CHANG CHUI AND A R DAMASIO
}

From the Department of Neurology (Division of Behavioral Neurology), University of Iowa College of
Medicine, Iowa City, Iowa

SUMMARY The handedness of seventy-five persons without evidence of neurological disease, was assessed with a standardised test. An analysis of the CT scans of the same persons was performed to determine (1) presence and lateralisation of frontal and occipital "petalia," (2) width of frontal and occipital lobes of each hemisphere, (3) direction of straight sinus deviation. Results suggest that handedness and cerebral asymmetries are independent variables. There were no significant differences between right-handers and non-right-handers. Also there were no significant differences between strongly left-handed and ambidextrous individuals, nor were there differences between righthanders with or without family history of left-handedness. Irrespective of handedness, left occipital "petalia" was more common than right $(\mathrm{p}<0.01)$, right frontal petalia was more common than left $(\mathrm{p}<0.01)$, and straight sinus deviation was more commonly toward the right. The study does not support the concept that cerebral "symmetry" or "reverse asymmetry" are associated with left-handedness or ambidexterity. The noted asymmetries are more likely to be direct correlates of cerebral language dominance, than of handedness. Furthermore, the possibility that outside forces acting on the bone contributes to the asymmetries cannot be excluded. CT scan may be of value as a direct predictor of cerebral dominance.

Since Geschwind and Levitsky ${ }^{1}$ first called attention to the asymmetry of the planum temporale in the human brain, further evidence has been marshalled to the effect that the two cerebral hemispheres are generally not the mirror images of each other. ${ }^{2-13}$ Possibly such structural differences relate to the functional specialisation of the hemispheres and further knowledge about these relations may be important for the understanding of normal and abnormal higher behaviour in humans. As a consequence the possibility that anatomical cerebral asymmetry might be evaluated in vivo by means of computed tomography was considered. The fact that an apparent pattern to asymmetries of the human skull had been identified strengthened the rationale for such an investigation.

Hadziselimovic and $\mathrm{Cus}^{2}$ examined 250 skulls for local impressions, known as "petalias," formed by cerebral imprinting upon the inner

Address for reprint requests: Dr AR Damasio, MD, Department of Neurology, University of Iowa Hospitals and Clinics, Iowa City, Iowa 52242, USA.

Accepted 6 March 1980 table of the skull. In the posterior region, left occipital petalia was present in $36.8 \%$, right occipital petalia was noted in $19 \cdot 2 \%$, and symmetrical poles were found in $44 \%$. Associations between left occipital petalia and right frontal petalia on the one hand, and between right occipital petalia and left frontal petalia on the other, were also described. Looking at the skull and brain by means of CT scan imaging, LeMay ${ }^{9}$ noted the presence of left occipital petalia in $69 \%$ of her 158 right-handed subjects, right occipital petalia in $9 \%$ and occipital symmetry in $22 \%$. Frontal asymmetries, although less striking, were also noted: right and left frontal petalia being observed respectively in $30 \%$ and $7 \%$. When the width of the frontal and occipital lobes was considered, similar asymmetries were noted. In the occipital region, $64 \%$ showed wider left hemispheres, and $16 \%$ showed wider right hemispheres. On the other hand, measurement in 62 left-handed individuals while showing a similar pattern of petalias, revealed a reversed pattern of asymmetry in the occipital area with regard to width. Predominance of the right side was present in $46 \%$ and predominance 
of the left was measured in $22 \%$, while for the frontal regions the pattern was similar to that seen in right-handers albeit less pronounced.

In an attempt to replicate LeMay's findings and to find potential new clues of cerebral asymmetry we undertook a study of normal CT scans in right-handed and non-right-handed subjects assessed with a handedness questionaire, and in whom family handedness was also investigated.

\section{Materials and methods}

Seventy-five Mark III EMI compu:ed tomograms of the head $(160 \times 160$ matrix) were used in the study. Each patient had received an inventory enquiring into the strength of their own handedness and the similar preferences of the:r first degree relatives. ${ }^{14}$ Fif ty patients had always used their right hand for most skilled activities and constituted the righthanded group. Twenty-five persons utilised their left hand in a variety of daily activities and composed a group of non-right-handers. Twelve among the latter group were classified as strongly left-handed on the basis of a sinistral preference in most skilled activities. Thirteen persons who could use either hand for a number of skilled activities formed the ambidextrous subset of the non-right-handed group. Mean ages of the right- and non-right-handed groups were comparable: $44 \cdot 2$ and $39 \cdot 3$ years, respectively.

Sixty-two of the 75 CT scans were read as completely normal. Thirteen scans, in which there were no focal findings but in which cerebral atrophy, cerebellar atrophy, and small ventricles were noticed, were also included. These changes were not considered likely to have affected the configuration of the inner table of the skull or the midline structures which represent the crucial determinants for the symmetry measurements.

The scans were generally obtained in a set of parallel planes angulated 15 degrees to the orbitomeatal line. The lowest section disclosing both the frontal horns and trigone was chosen for the assessment of hemispheric asymmetries. In all but seven of the cases, the CT scans were permanently recorded on transparent films. Using an overhead viewer, these were projected to approximately $80 \%$ original head size, and the contours of the inner table of the skull and the midline identifying structures were traced. In the seven cases in which the scans were recorded on $3 \times 4$ inch Polaroid prints, the above features were traced directly.

The sagittal line was drawn through the anterior falx, septum pellucidum and pineal gland (fig 1). Not infrequently, the straight sinus or posterior falx or both angulated to either side of the midline. Hence these posterior structures could not be reliably included in the sagittal line determination.

Perpendiculars to the sagittal plane were then drawn at the most anterior and posterior extents of the inner table, thereby defining the antero-posterior diameter of the skull (AP). Where there was asymmetry in the frontal or occipital protuberances, the degree of petalia (PET) was quantified by dividing the differences in the antero-posterior projection $\left(\mathrm{L}_{\mathrm{R}}-\mathrm{L}_{\mathrm{L}}\right)$ by the AP diameter of the skull: PET= $\left(L_{R}-L_{L}\right) / A P$. Thus right-sided petalia was indicated by positive PET values and left-sided petalia was represented by negative PET values.

Note was also made of straight sinus deviation. These observations were annotated as follows: $S=E$ (no angulation); $\mathbf{S}=\mathbf{R}$ (angulation to the right posteriorly); and $\mathrm{S}=\mathrm{L}$ (angulation to the left posteriorly).
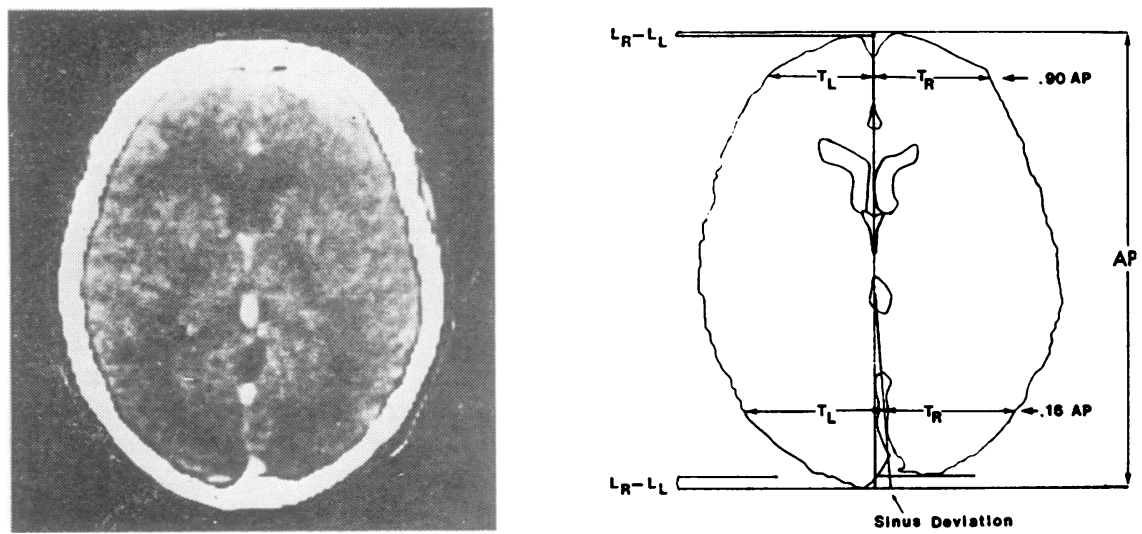

Fig 1 Principal measurements used to assess petalia and degree of cerebral a:ymmetry. $A P=$ antero-posterior diameter. $0.16 \mathrm{AP}$ and $0.90 \mathrm{AP}=$ levels at $16 \%$ and $90 \%$ of AP length (measured from most posterior point) used to determine transverse diameter. $T L$ and $T R=$ left and right transverse diameters of cerebrum (occipital $T L$ and $T R$ are determined at $0.16 \mathrm{AP}$; frontal $T L$ and $T R$ at $0.90 \mathrm{AP}$ ). LL and $L R=$ length of left and right hemisphere, used to determine petalia. 
Additional lines were drawn perpendicular to the sagittal line at points lying at distances $16 \%$ and $90 \%$ of the total posterior to anterior diameter of the skull. These points were selected so that their respective perpendiculars would traverse the occipital lobes and the region of the middle inferior frontal gyrus respectively. The right and left transverse dimensions were compared in each region by dividing their differences by their sums:

$$
\mathrm{W}=\frac{\left(\mathrm{T}_{\mathrm{R}}-\mathrm{T}_{\mathrm{L}}\right)}{\left(\mathrm{T}_{\mathrm{R}}+\mathrm{T}_{\mathrm{L}}\right)} .
$$

Again positive values signifies right-sided predominance and negative values indicated left-sided predominance. Differences were recorded if the absolute value of $\mathrm{W}$ was equal or grea+er than 0.02 , which corresponded to a measured difference of approximately $1 \mathrm{~mm}$ (accuracy of the millimeter rule).

Within group differences were evaluated using a two-tailed sign test. Between group differences were assessed by means of the chi-squared test.

Inherent in the methodology described above are several limitations of accuracy and reliability. There is variability in the planes of section. In persons with limited neck mobility planes of section may parallel the orbito-meatal line (that is, zero degree inclination). Various degrees of horizontal tilt (for example, left side positioned higher or lower than the right) also introduce error. Furthermore, there are individual variations in overall skull proportions.
These differences were minimised by using relative rather than absolute points for measurement. For example, the anterior hemispheric widths were estimated at points lying $90 \%$ of the distance from the occiptal to the frontal pole, and not at a fixed distance from one pole. Obviously there was also possible error in tracing the inner table of the skull and determining the sagittal plane. For this reason we estimated the reliability of measurements by comparing duplicate sets of measures independently obtained on a separate occasion. Overall reproducibility was good. Differences were, in this sample, always in determining the presence or absence of significant asymmetry. No gross discrepancies, such as finding predominance of the right side on one occasion and predominance on the left side on another, were ever encountered. Reliability was also assessed in relation to level of CT cut, in regard to direction of asymmetry. This proved reliable, the direction of asymmetry being the same regardless of the cut chosen to investigate it.

\section{Results}

\section{A Cerebral asymmetries in right-handers}

Table 1 and fig 2 summarise the pertinent data. In $56 \%$ of 50 right-handers no frontal petalia was found. However, right frontal petalia was more common $(36 \%)$ than left $(8 \%)(p<0.01)$. At the posterior pole, left occipital petalia was present in over half of the cases $(60 \%)$. The

Table 1 Distribution of cerebral asymmetries in right-handers and non-right-handers

\begin{tabular}{|c|c|c|c|c|c|c|c|c|c|c|c|c|c|c|c|}
\hline & \multicolumn{3}{|c|}{ Frontal petali } & \multicolumn{3}{|c|}{ Occipital petalia } & \multicolumn{3}{|c|}{ Sinus deviation } & \multicolumn{3}{|c|}{ Frontal width } & \multicolumn{3}{|c|}{ Occipital width } \\
\hline & $R$ & $L$ & $E$ & $\bar{R}$ & $L$ & $E$ & $R$ & $L$ & $E$ & $R$ & $L$ & $E$ & $R$ & $L$ & $E$ \\
\hline $\begin{array}{l}\text { Right-handers } \mathrm{N}=50 \\
\text { Non-right-handers } \mathrm{N}=25\end{array}$ & $\begin{array}{l}36 \\
28\end{array}$ & $\begin{array}{r}8 \\
16\end{array}$ & $\begin{array}{l}56 \\
56\end{array}$ & $\begin{array}{l}20 \\
20\end{array}$ & $\begin{array}{l}60 \\
44\end{array}$ & $\begin{array}{l}20 \\
36\end{array}$ & $\begin{array}{l}20 \\
24\end{array}$ & $\begin{array}{l}8 \\
0\end{array}$ & $\begin{array}{l}72 \\
76\end{array}$ & $\begin{array}{l}36 \\
48\end{array}$ & $\begin{array}{l}22 \\
20\end{array}$ & $\begin{array}{l}42 \\
32\end{array}$ & $\begin{array}{r}20 \\
4\end{array}$ & $\begin{array}{l}36 \\
64\end{array}$ & $\begin{array}{l}44 \\
32\end{array}$ \\
\hline
\end{tabular}

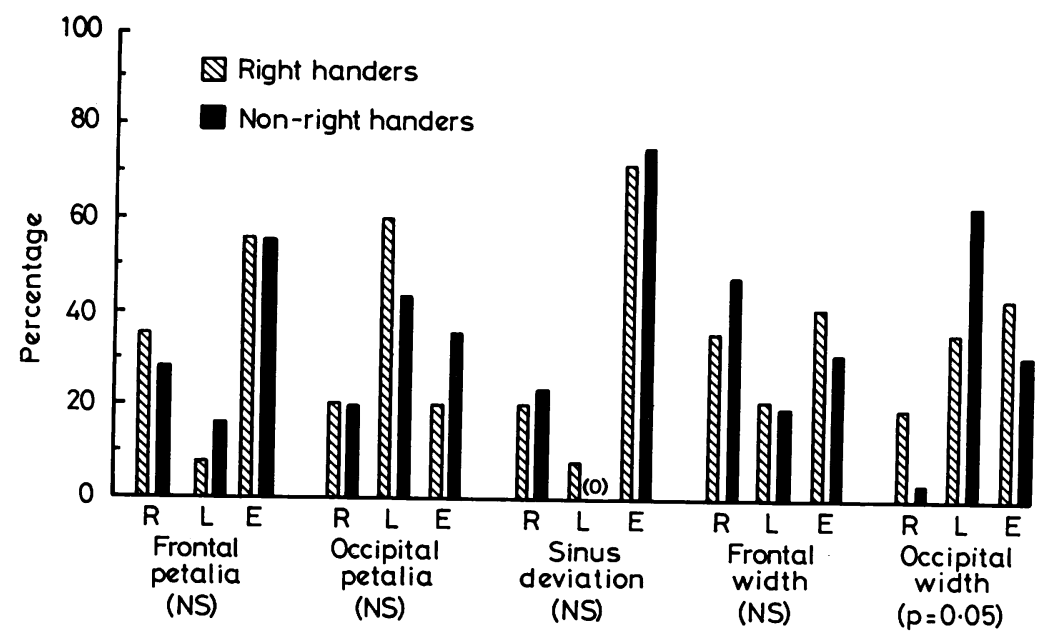

Fig 2 Histogram depicts relative percentage of frontal and occipital petalia, direction of sinus deviation, and frontal and occipital width predominances in the overall population of right-handers and non-right-handers. $R=$ right $; L=$ left $; E=$ equal; $N S=$ non-significant difference between right-handers (crossed bars) and non-righthanders (black bars). 
remaining cases were equally distributed $(20 \%$ each) between right occipital petalia and occipital symmetry. Asymmetry of occipital petalia reached statistical significance $(p<0.01)$. It should be noted that occiptal petalia was more apparent than frontal petalia on gross inspection.

Usually $(72 \%)$ the straight sinus assumed a fairly straight antero-posterior course. When deviation was present, however, it was more frequently found directed toward the right $(20 \%$,$) a significant value (one-tailed t$ test, $\mathrm{p}<0.05)$.

The pattern of asymmetries for anterior and posterior hemispheric width was similar to but less marked than for petalia. In $42 \%$ of the scans the frontal lobes were symmetrical in width. The right side was wider in $36 \%$, and the left side was greater in $22 \%$. Reversed findings characterised the occipital region. The hemispheres were symmetrical in $44 \%$ of the cases. But here left-sided predominance of the left side was more common than of the right $(36 \%$ versus $20 \%$ respectively). Neither of the hemispheric width differences were statistically significant.

$B$ Cerebral asymmetries in non-right-handers Table 1 and fig 2 summarise the data. In the majority $(56 \%)$ of 25 non-right-handed persons, no significant frontal petalia was present. However, right frontal petalia was slightly but not significantly more common $(28 \%)$ than left-sided petalia $(16 \%)$. Left occipital petalia was found in $44 \%$ and was absent in $36 \%$. Right occipital petalia was seen in $20 \%$ of the cases. These differences were not significant.

Sinus deviation was absent in three-quarters of the cases. When present in this sample of non-right-handers, deviation was invariably to the right, posteriorly $(p<0.05)$.

The right frontal hemispheric width was larger than the left in $48 \%$. The opposite was true in
$20 \%$. No frontal width asymmetry was found in $32 \%$ (non-significant findings). In the occiptal area, the left hemisphere measured wider in $64 \%$ of non-right-handers. In only one case $(4 \%)$ was the right side predominant. These differences are significant for $p<0.001$. No asymmetry was seen in $32 \%$ of the cases.

\section{Comparison of asymmetries in right-handers} versus non-right-handers

Applying the chi-squared test with two degrees of freedom, a comparison of cerebral symmetries was undertaken for right-handed and non-righthanded subjects. The null hypothesis was formulated as follows: Handedness and CT cerebral asymmetries are independent.

In only one set of comparisons could the null hypothesis be rejected: Left occipital width predominance was found more frequently in nonright-handers than in right-handers $(p=0.05)$. This is at variance with findings previously feported in the literature. ${ }^{9}$ Frontal and occipital petalia, frontal hemispheric width, and direction of straight sinus deviation did not differ significantly between right-handers and non-righthanders ( $\mathrm{p}$ values ranging from 0.35 to 0.60 ).

\section{$D$ Cerebral asymmetries in relation to} strength of handedness

A chi-squared comparison of cerebral asymmetries between 12 strongly left-handed individuals and 13 ambidextrous persons revealed no significant differences. A summary of pertinent data is presented in table 2 .

\section{E Cerebral asymmetries in relation to familial handedness}

Among the 50 right-handers, 33 had a strong family history of right-handedness (all first degree relatives were right-handers). In 17, at least one first degree relative was not right-handed. A

Table 2 Distribution of asymmetries in ambidextrous and strongly left-handed persons

\begin{tabular}{|c|c|c|c|c|c|c|c|c|c|c|c|c|c|c|c|}
\hline & \multicolumn{3}{|c|}{ Frontal petalia } & \multicolumn{3}{|c|}{ Occipital petalia } & \multicolumn{3}{|c|}{ Sinus deviation } & \multicolumn{3}{|c|}{ Frontal width } & \multicolumn{3}{|c|}{ Occipital width } \\
\hline & $\bar{R}$ & $L$ & $\bar{E}$ & $R$ & $L$ & $\bar{E}$ & $R$ & $L$ & $E$ & $\bar{R}$ & $L$ & $E$ & $R$ & $L$ & $E$ \\
\hline $\begin{array}{l}\text { Ambidextrous } N=13 \\
\text { Strong } \mathrm{LH} \mathrm{N}=12\end{array}$ & $\begin{array}{l}4 \\
3\end{array}$ & $\begin{array}{l}3 \\
1\end{array}$ & $\begin{array}{l}6 \\
8\end{array}$ & $\begin{array}{l}3 \\
2\end{array}$ & $\begin{array}{l}5 \\
6\end{array}$ & $\begin{array}{l}5 \\
4\end{array}$ & $\begin{array}{l}2 \\
4\end{array}$ & $\begin{array}{l}\mathbf{0} \\
\mathbf{0}\end{array}$ & $\begin{array}{r}11 \\
8\end{array}$ & $\begin{array}{l}5 \\
7\end{array}$ & $\begin{array}{l}3 \\
2\end{array}$ & $\begin{array}{l}5 \\
3\end{array}$ & $\begin{array}{l}1 \\
0\end{array}$ & $\begin{array}{l}8 \\
8\end{array}$ & $\begin{array}{l}4 \\
4\end{array}$ \\
\hline
\end{tabular}

Table 3 Cerebral asymmetries in right-handers with and without family history of non-right-handedness

\begin{tabular}{|c|c|c|c|c|c|c|c|c|c|c|c|c|c|c|c|}
\hline & \multicolumn{3}{|c|}{ Frontal petalia } & \multicolumn{3}{|c|}{ Occipital petalia } & \multicolumn{3}{|c|}{ Sinus deviation } & \multicolumn{3}{|c|}{ Frontal width } & \multicolumn{3}{|c|}{ Occipital width } \\
\hline & $\bar{R}$ & $L$ & $E$ & $\bar{R}$ & $L$ & $E$ & $R$ & $\bar{L}$ & $E$ & $R$ & $L$ & $E$ & $\bar{R}$ & $L$ & $E$ \\
\hline $\begin{array}{l}\text { With Non-RH N }=17 \\
\text { Without Non-RH }\end{array}$ & 8 & 1 & 8 & 4 & 10 & 3 & 4 & 2 & 11 & 6 & 4 & 7 & 4 & 6 & 7 \\
\hline (i.e. all $\mathbf{R H}$ ) $\mathbf{N}=33$ & 11 & 3 & 19 & 6 & 20 & 7 & 6 & 2 & 25 & 12 & 7 & 14 & 6 & 12 & 15 \\
\hline
\end{tabular}


Table 4 Cerebral asymmetries in males and females (right-handers)

\begin{tabular}{|c|c|c|c|c|c|c|c|c|c|c|c|c|c|c|c|}
\hline & \multicolumn{3}{|c|}{ Frontal petalia } & \multicolumn{3}{|c|}{ Occipital petalia } & \multicolumn{3}{|c|}{ Sinus deviation } & \multicolumn{3}{|c|}{ Frontal width } & \multicolumn{3}{|c|}{ Occipital width } \\
\hline & $\bar{R}$ & $L$ & $E$ & $R$ & $L$ & $E$ & $R$ & $L$ & $E$ & $\bar{R}$ & $L$ & $E$ & $\bar{R}$ & $L$ & $E$ \\
\hline $\begin{array}{l}\text { Male } N=28 \\
\text { Female } N=22\end{array}$ & $\begin{array}{r}11 \\
7\end{array}$ & $\begin{array}{l}2 \\
2\end{array}$ & $\begin{array}{l}15 \\
13\end{array}$ & $\begin{array}{l}3 \\
5\end{array}$ & $\begin{array}{l}14 \\
18\end{array}$ & $\begin{array}{l}5 \\
5\end{array}$ & $\begin{array}{l}7 \\
3\end{array}$ & $\begin{array}{l}3 \\
1\end{array}$ & $\begin{array}{l}18 \\
18\end{array}$ & $\begin{array}{r}12 \\
7\end{array}$ & $\begin{array}{l}6 \\
4\end{array}$ & $\begin{array}{l}10 \\
11\end{array}$ & $\begin{array}{l}8 \\
2\end{array}$ & $\begin{array}{r}11 \\
7\end{array}$ & $\begin{array}{r}9 \\
13\end{array}$ \\
\hline
\end{tabular}

chi-squared comparison of CT cerebral asymmetries between these two groups identified no significant differences. Table 3 summarises the data.

\section{$F$ Cerebral asymmetrie: in relation to sex}

From the group of 50 right-handers with CT scans read as completely normal, there were 28 males and 22 females. A chi-squared test with two degrees of freedom revealed no significant differences in the findings of frontal petalia, sinus deviation, frontal hemispheric width or occipital hemispheric width predominance (table 4).

\section{$G \quad$ Interassociation of asymmetries}

Petalia occurred infrequently on the same side at both occipital and frontal poles (six cases). That is, in general either no petalia or contralateral petalia was found at opposite cerebral poles. Similarly, the side of hemispheric predominance usually did not concord for occipital and frontal regions.

On the other hand, in all but three cases petalia was associated with ipsilateral or absent hemispheric predominance for either occipital or frontal widths. Sinus deviation was associated with contralateral or absent petalia and occipital width predominance.

Similar interassociations of asymmetries were found in the 25 non-right-handed subjects.

In conclusion: (1) The noteworthy cerebral asymmetries found in our population were as follows: (a) Left occipital petalia was more common than right occipital petalia $(\mathrm{p}<0.01)$. (b) Right frontal petalia was more common than left frontal petalia $(\mathrm{p}<0.01)$, although the most common finding was no frontal petalia. (c) Straight sinus deviation, if present, was more commonly toward the right. (2) Handedness and cerebral asymmetries were found to be independent. (a) There were no significant differences between right-handers and non-right-handers. (b) There were no significant differences between strongly left-handed and ambidextrous individuals. (c) There were no significant differences in right-handers with or without a family history of non-right-handedness. (3) Cerebral asymmetries in right-handers were independent of sex.

\section{Discussion}

Our findings confirm the existence, in the majority of subjects in our study, of a pattern of cerebral asymmetry detectable with CT, as described by LeMay. ${ }^{9}$ There is a consistent trend demonstrating that the posterior region of the left hemisphere is more often larger than the right. Similar trends of asymmetry have been noted by macroscopic measurements of the

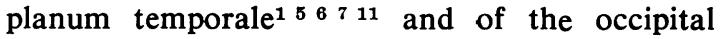
horn of the lateral ventricles, ${ }^{3}$ as well as by cytoarchitectonic comparisons of Wernicke's area. ${ }^{13}$ However, the pattern of CT asymmetry was seen irrespective of individual hand preference, the same being true for the lack of asymmetry or for the reversed asymmetry. Consequently, our study lends no support to the concept that cerebral "symmetry" or the presence of "reverse asymmetry" are, in some way, associated with left-handedness or ambidexterity. ${ }^{9}$

It is of note that the finding of "reverse asymmetry" in the CT scans of some right-handers is not as paradoxical as would first appear. It may correspond to right hemisphere language dominance in dextrals, a rare but well documented disposition which is at the origin of crossed aphasia in dextrals ${ }^{15} 16$ and which has been noted by Milner ${ }^{17}$ in studies using the Wada test.

The significance of these asymmetries is an unresolved question. They are more likely to be direct correlates of cerebral language dominance (or of its potential lateralisation) than of handedness. This would appear to be one more circumstance in which handedness may not reflect cerebral dominance for language as accurately as previously presumed. In fact, there is little doubt that the majority of individuals, regardless of hand preference, have left cerebral dominance for language (cf clinical neurological evidence from observation of the aphasias ${ }^{18}{ }^{19}$ as well as classic studies using the Wada test ${ }^{20}{ }^{21}$ ). Secondly, even in exclusively right-handed persons, the degree of language lateralisation which can be inferred from behavioral assessment is variable (cf Shankweiler and Studdert-Kennedy's study on handedness and speech lateralisation with dichotic listening). ${ }^{22}$ It may be that the organic substrate 
for such variation of degree of language dominance and for discrepancy between dominance and handedness, is reflected by the relative sizes of the posterior hemispheres. CT imaging would thus provide an index of language lateralisation more direct and accurate than handedness.

Should the CT scan provide a direct indication of language lateralisation, important assistance may be given to the calculation of neurosurgical risk and to the formulation of prognosis in aphasic syndromes. Early results regarding the latter, warrant some optimism, as Naeser and associates $^{21}$ have shown that right-handed global aphasics with "reverse asymmetry" seem to enjoy greater improvement than those with "regular" left hemisphere predominance, as had been suggested by Geschwind and associates. ${ }^{12}$

Finally, it should be noted that outside forces acting on the bone may contribute independently to the pattern of symmetry or asymmetry of the skull and cerebrum. Factors such as sleeping posture, particularly in infancy, and prolonged recumbency, may be of importance. In other words, it appears reasonable to conclude that the combined shapes of brain and skull are the result of a compromise between the (a) spatial demands of the brain (in itself influenced by genetical factors and by presence or absence of brain disease capable of modifying macroscopic structure) and (b) forces acting on the bone from the outside.

\section{References}

1 Geschwind N, Levitsky W. Human brain: leftright asymmetries in the temporal speech region. Science 1968; 161:186-7.

2 Hadziselimovic $H$, Cus $M$. The appearance of the internal structures of the brain in relation to the configuration of the human skull. Acta Anatomica 1966; 63:289-99.

3 McRae DL, Branch CL, Milner B. The occipital horns and cerebral dominance. Neurology 1968; 18:95-8.

4 LeMay M, Culebras A. Human brain-Morphologic differences in the hemispheres demonstrable by carotid arteriography. $N$ Engl J Med 1972; 287:168-70.

5 Teszner D, Tzavaras A, Gruner J, Hecaein $\mathbf{H}$. L'asymetrie droite-gauche du planum temporale; a propos de l'etude anatomique de 100 cerveaux. Rev Neurol (Paris) 1972; 126:444-9.

6 Witelson S, Pallie W. Left hemisphere specialisa- tion for language in the newborn: Neuroanatomical evidence of asymmetry. Brain 1973; 96: 641-6.

7 Wada JA, Clarkek R, Hamm A. Cerebral hemispheric asymmetry in humans: cortical speech zones in 100 adult and 100 infant brains. Arch Neurol 1975; 32:239-46.

8 Hochberg FH, LeMay M. Arteriographic correlates of handedness. Neurology (Minneap) 1975; 25:218-22.

9 LeMay M. Morphological cerebral asymmetries of modern man, fossil man, and non-human primates. Ann N Y Acad Sci 1976; 280:349-66.

10 Rubens AB, Mahowald MW, Hutton JT. Asymmetry of the lateral (Sylvian) fissures in man. Neurology (Minneap) 1976; 26:620-4.

11 Chi JG, Dooling EL, Gilles FM. Left-right asymmetries of the temporal speech areas of the human fetus. Arch Neurol 1977; 34:346-8.

12 Galaburda AM, LeMay M, Kemper TL, Geschwind N. Right-left asymmetries in the brain. Science 1978; 199:852-6.

13 Galaburda AM, Sanides F, Geschwind N. Cytoarchitectonic left-right asymmetries in the temporal speech region. Arch Neurol 1978; 35:812--7.

14 Varney NR, Benton AL. Tactile perception of direction in relation to handedness and familial handedness. Neuropsychologia 1975; 13:445-54.

15 Ettlinger G, Jackson CV, Zangwill OL. Dysphasia following right temporal lobectomy in a right-handed man. J Neurol Neurosurg Psychiatry 1955; 18:214-7.

16 Zangwill OL. Two cases of crossed aphasia in dextrals. Neuropsychologia 1979; 17:167-72.

17 Milner B. Speech lateralisation, hand preference and gestural control: evidence from carotid amytal studies. 17th Annual Meeting of the Academy of Aphasia, San Diego, October 1979.

18 Zangwill OL. Cerebral Dominance and its Relation to Psychological Function. Edinburgh: Oliver and Boyd, 1960.

19 Goodglass H, Quadfasel FA. Language laterality in left-handed aphasia. Brain 1954; 77:521-48.

20 Wada $\mathbf{J}$, Rasmussen $\mathbf{T}$. Intracranial injection of sodium amytal for lateralisation of cerebral speech dominance. Experimental and clinical observations. J Neurosurg 1960; 17:266.

21 Branch O, Milner B, Rasmussen T. Intracarotid sodium amytal for the lateralisation of cerebral speech dominance. J Neurosurg 1964; 21:399-405.

22 Shankweiler D, Studdert-Kennedy M. A continuum of lateralisation for speech perception? Brain Lang 1975; 2:212-25.

23 Pieniadz JM, Naeser MA, Koff E, Levine HL. CT scan hemispheric asymmetry measurements and recivery in aphasia. 17th Annual Meeting of the Academy of Aphasia, San Diego, 1979. 